\title{
Trends in Inequality and Welfare in Consumption Expenditure: The Case of Pakistan
}

\author{
RASHIDA HAQ

\section{INTRODUCTION}

Economic growth is important, but at the same time it loses its importance if nothing trickles down to the poor. One of the frequent heard arguments against growth strategies is that it benefits only the comparatively well off segment of the society. This means that the concomitant of economic growth is more skewed income distribution. Growth and equity should be solved subsequently or in some cases simultaneously, otherwise these countries are exposed to disaster [Hirschman (1973)]. The surge for income distribution studies both in developed and developing countries has, however, been caused by different reasons. In a developed nation, a high economic growth, in terms of GNP per capita and the introduction of the concept of a welfare state necessitated a widespread debate on income inequality and relative poverty issues. In the developing countries, failure to achieve sustainable high growth rates and disappointment from the pursuit of growth-led macro-economic policies in the past decade has surfaced a need to conduct income distribution studies and policies.

Much of the recent literature on inequality and economic well-being in Pakistan has focused on the apparent increased inequality that occurred during the last two decades.

The results of both the inequality in income and consumption studies showed that overall inequality varied in the urban, rural sectors and overall Pakistan. Naseem (1973) concluded in his pioneering work that Gini-coefficients of expenditures as well as income have shown an increase in the inequalities in the year 1971-72. Cheema et al. (1984) showed that redistribution of income from rich to the poor households will raise the consumption demand for basic necessities like, wheat, pulses, edible oils, clothing and footwear, etc; while the demand for personal effects: meat, fish and poultry, furniture would decreased. Afridi et al. (1984) concluded that effect of inflation are highly non-egalitarian and in fact, contributed more to increase the existing inequalities in food expenditure than in non-food expenditure especially in lower income brackets. Ercelawn (1988) argued that using consumption instead of income yields different results about expenditure inequality over time. Ahmed and Ludlow (1989) explored that only a little change in income and expenditure inequality has taken place during 1979 and 1984-85. Jehle (1990) found that strong Islamabad.

Rashida Haq is Research Economist at the Pakistan Institute of Development Economics, 
evidence is found that real expenditure inequality in Pakistan improved from 198485 to 1987-88. Malik (1993) computed that inequality in income and expenditure per person among all households increased within provinces and agroclimatic zones during 1984-85 to 1987-88. Kemal (1994) reached the generally-led conclusion that "Structural Adjustment Program" had contributed towards efficiency, but had adverse implications for employment and equity. Jaffri and Khattak (1995) suggested that inequality is consistently higher in urban areas than in rural areas and it increased sharply in 1990-91 in both sectors.

On the basis of various studies on income distribution, it is found that income inequality is greater than expenditure inequality because the life-cycle hypothesis suggests that people smooth their consumption over their lifetimes, so that even if income varies significantly over the life-cycle consumption would be less variable than income from year to year.

Earlier studies, however, have not given much emphasis to the importance of localising various categories of inequality because different types of inequality require different policy instruments. The available literature on income inequality in Pakistan is lacking in evaluating the economic welfare through the index developed by Sen (1974). Most of the research has not used the consistent data series to examine the income inequality in Pakistan.

The major contribution of this study is that it provides a decomposition analysis of consumption expenditure to measure inequality in urban rural sectors and in overall Pakistan, which are lacking in earlier studies. The analysis is based on "equivalent consumption-expenditure" per person as it confirms to the welfare theory underlying inequality and poverty [Blundell and Preston (1991)]. It also provides a consistent series of level of consumption expenditure from 1979 to 1992-93 on a single base that is 1992-93 prices. The study is confined to welfare index proposed by Sen (1974) as a basis for analysing welfare in Pakistan. One of the advantages of this index is that it takes into account both the size and distribution of income.

The study attempts to answer the following questions such as: what is the real average consumption-expenditure of the population? What is the extent of inequality of consumption-expenditure and in which way it is moving? How do the various consumption expenditure components effect the total welfare? How do the price changes affect the welfare levels of the population?

The study is organised into four chapters. Following introduction, Section II discusses methodology and data. Section III is devoted to the analysis of expenditure inequality and welfare. Section VI summaries and brings together the main conclusions of this study.

\section{METHODOLOGY}

This chapter examines methodological issues in the level and distribution of consumption expenditure and the measurement of economic welfare. 


\section{Measures of Welfare}

In measuring inequality consumption expenditure is used an appropriate indicator of economic well-being because utility is derived from the consumption of goods and services and also a better indicator of "Permanent Income". Results from the "Household Income and Expenditure Survey"(HIES) have shown that when consumer units are classified by income, the expenditure-to-income ratio is quite high for the lowest tail of income distribution through incurring of indebtedness. Conversely, in the upper tail, the consumer units report high levels of income but low level of spending through saving. As the main concern is with the welfare levels of individual, it is reasonable to derive the measurement of welfare from individual consumption expenditure by applying a complete single measure of welfare. Sen (1974) consider the following welfare function.

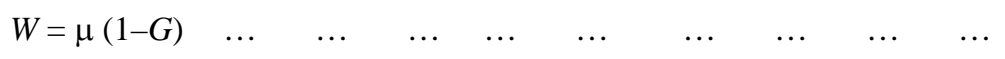

Where $\mu$ is the mean expenditure of the society and $G$ is the Gini-coefficient. The parameter $\mu$ only considers per capita expenditure and ignores inequality whereas $G$ considers inequality and ignores the level of expenditure. Sen index combines both. Gini-coefficient ranges between 0 for complete equality and 1 for complete inequality.

\section{Welfare by Expenditure Components}

As the adult equivalent consumption expenditure is the sum of several consumption expenditure components, it is useful to decompose total welfare into various expenditure components. According to Foster (1984) the chosen measure should have five basic properties, (1) Pigou-Dalton transfer sensitivity, (2) symmetry, (3) mean independence, (4) population homogeneity, and (5) decomposability. Both the Gini index and Sen's index possess this property. In this paper this methodology is used to analyse the contribution of each expenditure component to total welfare as it has all the above five properties.

Suppose there are $n$ expenditure components, $\mu$ is the mean consumption expenditure and $\mu_{i}$ is the mean of the $i$ th components. Then it can be written:

$$
\begin{array}{llllllllll}
\mu=\sum_{i-1}^{n} \mu_{i} & \ldots & \ldots & \ldots & \ldots & \ldots & \ldots & \ldots & \ldots & \ldots
\end{array}
$$

Likewise the decomposition of Gini index of total expenditure in terms of expenditure components can be expressed as [Kakwani (1980)]:

$$
\begin{array}{lllllll}
G=1 / \mu \sum_{i=1}^{n} \mu_{i} C_{i} & \ldots & \ldots & \ldots & \ldots & \ldots & \ldots
\end{array}
$$


Where $C_{i}$ is the concentration index of the $i$ th expenditure component. The concentration index $C$, is the same as the Gini index except that the ranking of individuals is by the total expenditure and not the ith expenditure component. The concentration index of an expenditure component measure how evenly or unevenly that expenditure component is distributed as compared to distribution of total expenditure. If $C_{i}$ is greater (smaller) than $G$, it implies that the ith expenditure component is distributed more (less) unevenly as compare to total consumption expenditure.

Equation (1) with (2) and (3) can then be used to express the total welfare as:

$$
\begin{array}{lllllll}
W=\sum_{i=1}^{n} \mu_{i}\left(1-C_{i}\right) & \ldots & \ldots & \ldots & \ldots & \ldots & \ldots
\end{array}
$$

Where $W$ expressed the total welfare, which is decomposed in terms of individual expenditure components; $\mu_{i}\left(1-C_{i}\right)$ being the contribution of the $i$ th expenditure component to total welfare.

\section{The Effects of Price Changes on Total Welfare}

To evaluate the effects of price changes on the total welfare the following equation expresses the price elasticity of aggregate welfare as Kakwani (1995):

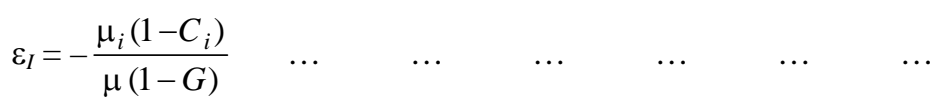

Where $\mu_{\mathrm{i}}$ is the mean expenditure on the ith item and $C_{i}$ is the concentration index of the ith item. The above elasticity which is always negative shows that if the price of the ith item increases by 1 percent, then the aggregate welfare will change by $\varepsilon_{I}$ percent. So $\varepsilon_{I i}$ can be used to evaluate the effect of price change on the total welfare.

\section{The Data}

This study covers the period from 1979 to 1992-93 using data from "Household Income and Expenditure Surveys" (HIES). To compare welfare and income distribution across different time periods one needs to adjust the distribution given in current prices for price changes over time. All the published data are made consistent on a single base that is 1992-93 prices by using the official consumer price indices. To account for the size and age composition of household, all the expenditure statistics are adjusted by modifying the OECD (1982) equivalence scale.

So the number of adult equivalent in a household size adjusted for age composition, $N$ can be calculated as:

$$
N=X_{1}+0.7 X_{2}+0.6 X_{3}
$$

Where $X_{1}$ is the number of earners in the household, $X_{2}$ is the number of other adults 
and $X_{3}$ is the number of children of age less than sixteen years.

The consumption expenditure considers the following decomposition.

(1) Food; (2) Clothing and footwear; (3) Housing; (4) Fuel and lighting; (5) Furniture, fixture and furnishing; (6) Health; (7) Transportation and Communication; (8) Cleaning and laundry; (9) Education, recreation and entertainment; and (10) Other miscellaneous.

\section{RESULTS AND ANALYSIS}

This section examines patterns and trends in adult equivalent consumptionexpenditure by factor components. It also explains the contribution of various expenditure categories in the overall expenditure inequality and welfare.

\section{An Analysis of Adult Equivalent Consumption- expenditure in Pakistan}

Table 1 presents the real annual equivalent consumption expenditure and its percentage share in different components. It shows that the level of consumption is greater in urban sector than in the rural sector and in overall Pakistan during the years 1979 to 1992-93. The average annual consumption has increased over time except in 1987-88. The increase in expenditure was due to growth in gross domestic product and employment, which was at the rate of 6.2 percent and 2.5 percent respectively over the years 1984-85 to 1987-88. The higher growth of employment led to growth of wages at the rate of 8.4 percent in the large scale of manufacturing sector, of 5.4 percent in the agriculture sector, of 1.8 percent of unskilled workers. In years the 1987-88 to 1990-91, the wages of unskilled workers declined which form the bulk of the poor both in the rural and the urban areas [Amjad and Kamal (1997)]. In 1992-93 the level of consumption expenditure has increased significantly in all areas. The system of Zakat and Ushr and Bait-ul-mal have also contributed in increasing the level of consumption of the lowest income groups. The growth in consumption expenditure is much greater in the urban sector than in the rural sector.

The total expenditure is further decomposed into ten components namely, Food; Clothing and footwear; Housing; Fuel and lighting; Furniture, fixture and furnishing; Health; Transportation and Communication; Cleaning and laundry; Education, recreation and entertainment and miscellaneous items. 'Food' expenditure contributes highest share than other components and its percentage share is also greater in the rural sector. Although the share of expenditure on food has decreased slightly, but the average consumption expenditure on food has increased during the period of analysis. This is, obviously an expected result because the expenditure on food has not risen as income (Engle's Law).

Coming to the structure of non-food consumption categories, the percentage share in 'clothing and footwear' has decreased from 1979 and onward. There is not 
Table 1 
much difference in consumption between the two sectors and overall Pakistan. 'Housing' contributes highest share in non-food consumption and its share continuously increasing overtime in the urban sector except in 1987-88. In the rural sector, this share is increasing slightly overtime. There is a slight difference in the share of consumption of 'fuel and lighting' between urban and rural sectors. Although the urban households generally consume more energy than the rural households but they have easier access to cheaper energy types such as electricity and natural gas. The consumption share of 'furniture and fixture' not varies widely in all areas but it increased in 1992-93. The welfare indicators like health and education depicted an interesting trend. It is observed that the difference in health expenditure share between the two sectors has been quite small while the consumption share of education among urban households has been substantially larger than among the rural households. The expenditure share on 'transportation and communication' has not depicted a smooth trend in all areas.

\section{Trends in Consumption-expenditure Inequality}

Table 2 explores the disparity in equivalent consumption expenditure in the urban and rural sectors and in overall Pakistan during the years 1979 to 1992-93. The estimated values of Gini-coefficient for total consumption and concentration index for its components are also presented. Gini-index for consumption disparity shows a relatively equal distribution of consumption among individuals in all areas but its level is greater in the urban sector. It is also evaluated that the level of inequality does not change much during the analyses period as the life-cycle hypothesis suggests that people smooth their consumption over lifetimes so that even if income varies significantly over life-cycle consumption would be less variable than income from year to year.

The major finding in this paper results from the concentration index expressed in ten components. This concentration index measures how evenly or unevenly that component is distributed as compare to total consumption. Table 2 shows that the 'food' expenditure is less than Gini-index for total expenditure, which shows that it is evenly distributed over that entire period of analysis except in 1979 in urban sector. Much variation is found when 'food' expenditure is further decomposed by its factor components. The concentration index for 'meat, fish and poultry' and 'fruits' are more unevenly distributed in all areas [Haq (1998)]. It is also mentioned that inequality in food consumption is always greater in the urban sector than in the rural sector.

The non-food consumption-expenditure categories are generally appeared to be more unevenly distributed than the overall expenditure. A major factor appears to be the growing disparity in consumption expenditure on housing within the urban sector over the entire period of analysis. The concentration index indicates that 
Table 2 
inequality in consumption expenditure on 'fuel and lighting' is not varied over time in all areas but much variation is found in consumption of kerosene oil and gas [Haq (1998)]. As far as disparity in consumption for 'furniture and fixture' is concerned it has shown no smooth trend and also unevenly distributed in favour of rich families. The inequality in 'health' expenditures not varied much up till 1987-88 in all areas but it sharply decreased in 1992-93 in the rural sector as the public expenditure increased 0.6 percent of GDP in the year 1990-91. The consumption inequality on 'education' indicates that it is unevenly distributed up till 1987-88 and then the trend changed drastically towards equality as the public expenditure on primary education increased. As these inequality measures have indicated that non-food consumption expenditures are relatively unevenly distributed over the total expenditure during the analysis period. Thus it can be argued that these consumption inequalities cause social tensions, class-conflict and unrest, culminating in head-on-confrontation between social and political interests [Peerzade (1997)].

\section{Trends in Economic Welfare}

In Table 3 individual welfare by consumption expenditure and its components are analysed by applying Sen (1974) welfare index which takes into account both the size and distribution of expenditure.

The estimates indicates that the overall economic welfare level has increased in two sectors and in Pakistan during the period 1979 to 1992-93. The level is greater in magnitude in the urban sector as compared to the rural sector due to high level of individual consumption and also a high level of inequality. However, it should be noted that increasing inequalities do not necessarily imply decreasing welfare

Decomposition of total welfare provides the contribution of consumption source to total welfare. It is evaluated that the food expenditure has contributed the highest level of economic welfare and its magnitude is maximum in 1992-93 in all areas. The urban sector contribution of welfare is always higher for all the years in the case of 'housing'. In the case of 'fuel and lighting' the welfare levels are similar in all areas. Growing electrification and a change away from traditional means of fuel and lighting in the rural areas may explain this phenomenon. The welfare levels for 'clothing and footwear', 'furniture and fixture' 'health' and 'cleaning and laundry' have similar trends. Although the welfare level from 'education' has increased in rural sector but still there is a great difference between the welfare levels of two sectors.

\section{The Effects of Price Elasticity on the Aggregate Welfare}

The effects of price changes on the aggregate welfare indicates that if the price of $i$ th commodity increases by one percent then the aggregate welfare changes by $\varepsilon_{I}$ percent, thus the individual should be given an additional income in order to remain at the same level of welfare as before. 
Table 3 
Table 4 presents the effects of price changes on aggregate welfare level. It is indicated that a given percentage change in price of total food item has a larger effect on aggregate welfare than the price change in any other components of expenditure during 1979 to 1992-93 in all areas. This happens because in total expenditure 'food' consumption has contributed more or less fifty percent of total expenditure. The estimates have also shown that the price responsiveness for food consumption is greater in the rural sector.

The low price elasticity effects on non-food expenditure components such as 'clothing and footwear' and 'cleaning and laundry', have shown no significant changes between 1979 to 1984-85. 'Furniture and fixture' has shown no significant change over time in all areas. 'Housing' has revealed greater price elasticity of welfare in the urban sector. In the rural sector 'education' has shown a drastic increase in price elasticity of welfare in 1992-93.Thus these price elasticities of welfare provide a link between total welfare and expenditure components.

\section{CONCLUSIONS}

This paper presents an analysis of inequality and welfare by using equivalent consumption-expenditure since it may be a better proxy for economic well-being. The study is based on "Household Income and Expenditure Survey" data for the years 1979 to 1992-93. Sen welfare index is used to determine the level of disparities in different section of the society.

The result confirmed that the level of consumption increased but inequality did not varied much overtime. The level of consumption and inequality remained high among urban households. The components of expenditure have shown that the disparity in food consumption is not high as compared to non-food consumption expenditure. It is also pointed out that non-food expenditure is more unevenly distributed among individuals in the urban sector as compared to rural sector. As far as economic welfare is concerned its level increased over time and its magnitude is greater in the urban sector. It is also evaluated that 'food' and 'housing' components of expenditure are the major contributors in total welfare. The price elasticity of welfare has shown that 'food' expenditure is more responsive in price changes in all areas. Thus, this paper provides a basis for determining the sources and magnitude of inequality and welfare of the population. So it is important to adopt the most efficient ways of directing expenditure towards various population subgroups. Obviously the most efficient policy will be to target expenditure to the poorest section of the population by slowing down inflationary tendencies, through a progressive tax structure system, reducing fiscal deficit and increasing the share of public expenditure on primary education and rural health facilities. Finally, the systems of Zakat and ushr should be effective and transparent so as it benefits the vulnerable groups of the society. 
Table 4 


\section{REFERENCES}

Afridi, U., A. Qadir, and J. Zaki (1984) Effect of Dual Sector Inflation across Income Levels in Pakistan. The Pakistan Development Review 23:2 and 3 381-390.

Ahmad, E., and Stephen Ludlow (1989) Poverty Inequality and Growth in Pakistan. The Pakistan Development Review 28:4 831-850.

Aamjad, R., and A. R. Kemal (1997) Macroeconomic Policy and their Impact on Poverty Alleviation in Pakistan. The Pakistan Development Review 36:1 39-68.

Blundell, R., and I. Preston (1991) The Distribution Between Income and Consumption in Measuring the Distribution of Household. (Welfare Institute for Fiscal Studies Working Paper.)

Cheema, Aftab Ahmad, and Muhammad Hussain Malik (1984) Consumption and Employment Effects of Income Redistribution in Pakistan. The Pakistan Development Review 23:2 and 3: 347-360.

Ercelawn, A. (1988) Income Inequality in Pakistan During the 70s: Issues in Estimation. Applied Economic Research Centre, University of Karachi. (Discussion Paper No. 92.)

Fostor, J., J. Greer, and E. Thorbecke (1984) A Class of Decomposable Poverty Measures. Econometrica 3: 761-766.

Haq, Rashida (1998) Inequality in Income, Expenditure and Welfare in Pakistan. Unpublished M.Phil Dissertation, Quaid-i-Azam University, Islamabad.

Hirschman, O. A. (1973) The Changing Tolerance for Income Inequality in the Course of Economic Development. The Journal of Economics 2: 544-566.

Jeffri, S. M. Y., and A. Khattak (1995) Income Inequality and poverty in Pakistan. The Pakistan Economic and Social Review 1\&2:165-193.

Jehle, A. Geoffrey (1990) Inequality in Pakistan: A Sectoral Welfare Approach. Pakistan Journal of Applied Economics 2: 165-193.

Kakwani, N. C. (1987) Income Inequality and Poverty: Method of Estimation and Policy Application. New York: Oxford University Press.

Kemal, A. R. (1994) Structural Adjustment, Employment, Income Distribution and Poverty. The Pakistan Development Review 4: 901-11.

Malik, Sohail J. (1993) Poverty in Pakistan, 1984-85 to 1987-88. In M. Lipton and J. van der Gaag (eds) Including the Poor. Washington, D. C: World Bank.

Naseem, S. M. (1973) Mass Poverty in Pakistan: Some Preliminary Findings. The Pakistan Development Review 12:4 317-360.

OECD (1982) The OECD List of Social Indicator. Organisation for Economic Cooperation and Development. Paris.

Peerzade, A. P. (1997) The Definition and Measurement of Poverty: An Integration and Income Distribution. The Pakistan Development Review 36:1 87-98.

Sen, A. K. (1974) Information Base of Alternative Welfare Approach: Aggregation and Income Distribution. Journal of Public Economics 3: 219-231. 